\title{
A Diagnostic System for State Grid's Operations
}

\author{
Jijun Wang1, Jing Tan², Lisha Gao', Hui Zhang ${ }^{3}$ \\ ${ }^{1}$ Jiangsu Power Company of State Grid, Nanjing, China \\ ${ }^{2}$ Jiangsu Electric Power Information Technology Co. Ltd., Nanjing, China \\ ${ }^{3}$ Zhongdianpuhua Information Technology Co., Ltd., Beijing, China \\ Email: zhangcaihb1992@163.com
}

Received 30 March 2016; accepted 18 July 2016; published 25 July 2016

\begin{abstract}
This paper introduces the key technologies in the company's operations and diagnostic analysis methods, including data adjustment method, empirical modeling, structural analysis, trend analysis and forecasting techniques, early warning analysis techniques. Then, empirical models was built based on the operational data of State Grid, the performance of the company was assessed to help find the problems in operations. This study provided the basis for the enterprises to monitor and understand the influence of the market or other external factors on the implementation of the enterprise strategic objectives.
\end{abstract}

\section{Keywords}

Operations Diagnosis, Empirical Analysis, Time Series, Forecast and Early Warning

\section{Introduction}

Enterprise diagnosis is a new management mode which is designed to help enterprises to eliminate the shortcomings of the management, make full use of resources, improve economic benefits, and then guarantee the survival and development of enterprises in intense competition. Its essence is to understand the business situation, plan the enterprise's future and ensure sustained and stable development of enterprises [1].

As one of the state-owned backbone enterprises related to national energy security and national economy, State Grid's core business is the construction and operation of power grid. The basis mission of the company is to ensure the safety, economy, cleanliness and sustainability of power supply. In recent years, with the deepening of the electric power system reform and changes in the international and domestic environment, the new situation has emerged in the development of energy. In addition, the rapid development of china's economy and the improvement of people's living standard have put forward higher requirements for the security and stability of power grid, power quality and power supply service. Tremendous changes have taken place in the operation and management of State Grid's internal and external environment. Therefore, how to adjust company's development mode and implement new operation strategy that adapt to the new situation has become the major issues and tasks of State Grid which concerning the survival and development of the company. 


\section{Process}

As shown in Figure 1, in terms of overall execution, the basic sprit of company's operations diagnostic analysis is the comparison between the expected operating objectives and the actual operation results. If there is a discrepancy in the comparison, the diagnostic system may need to point out the error in operation process and make adjustment to improve.

In this process, if the expected operational goal is generated by the external or set by the leadership, the diagnostic process will be relatively simple. However, when the market mechanism is affected by many domestic and international factors, the enterprise's operation objectives usually will transfer dynamically with the changes in the market. In the state, the goal and function of enterprise diagnosis is assisting managers to get a clearer understanding of the interactive relationship between the business operations and market conditions.

The first step of enterprise's operations diagnosis system is data processing and adjustment (data cleaning). Based on the data characteristics the second step is to establish an empirical model under the concept of System Dynamics. In the general System Dynamics people learn the operation of a system by modeling based on the theory of Engineering Physics. But in the operating system of the enterprise, the general theoretical model is no longer applicable because the relationships between many indicators are disturbed by internal management decision-making and external market shocks. In the situation that there is no theoretical basis can fully meet the market phenomenon, the main purpose is to get an empirical model that consistent with the fact. Because the empirical model is established according to data's feature, regularly (usually every three months) verify and modify is necessary when adequate new data is obtained. Then, structural analysis, trend analysis, forecast analysis and early warning analysis can be done from the model. These three types of diagnostic analysis can help managers understand the interaction between business operations processes and market dynamics. The current operational measures can be optimized and improved according to these diagnostic results.

\section{Key Technologies}

The process of enterprise's operation diagnosis is introduced in the last section. The key technologies and methods used in the process will be discussed in this section, including empirical modeling, structural analysis, trend analysis, prediction and early warning technology [2].

\subsection{Empirical Modeling}

Univariate time series models, dynamic regression models and multivariate time series models are the modeling approaches mainly used in this paper.

\subsubsection{Univariate Time Series Models}

Univariate time series model is a general model which quantifies the relationship between the indexes' observed values before and after. The reason why the observed values before and after are relevant is that no matter individuals or institutions the behavioral decision they made has varying degrees of memorability. The basic function of time series model is allowing people to quantify the degree of the memorability contained in the indicators clearly [3].

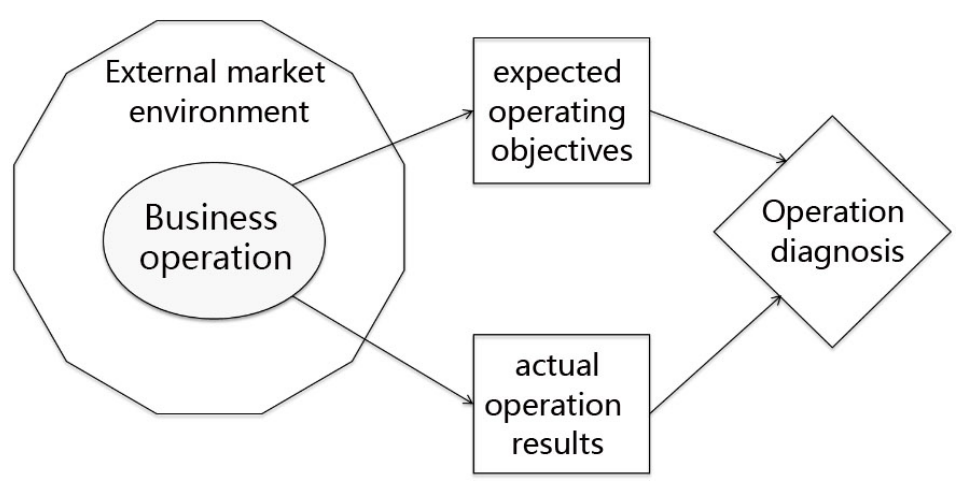

Figure 1. The basic sprit of company’s operations diagnostic. 


\subsubsection{Dynamic Regression Model}

How to model variables' memorial structure according to the past observed value is introduced before, and it is also the basis for predicting the future. In practice, commercial, economic and environmental related variables are often affected by known exogenous variables. For example, in the retail industry, commodity prices and advertising spending will affect sales [4]. In the financial sector, changes in interest rates will affect the stock price changes in some industries and so on.

Dynamic regression model include the lagging value of explanatory variable or response variable or them both. This model uses the transfer function to model the relationship between predictive variables and explanatory variables. When the explanatory variable is changed, the dynamic regression model can explain what will happen in the future.

\subsubsection{Multivariate Time Series Models}

Data of business, economics, engineering and environment are often collected in approximately equal time intervals, such as hourly, weekly, monthly or quarterly. Many problems, such time-series may be available in several related variables. It is not clear that which are the input indexes and which are the outputs. In the appliance industry, for example, the general manager of Haier is concerned about the sales of all the Haier household appliances: television, refrigerators and other related products. He would like to know whether the sales of different products are relevant and that is a similar situation. Overall, there are at least two reasons why we analyze such time series and find the pattern together:

1) To understand the dynamic relationship between them. They may be synchronous correlation; one timeseries may be ahead of another or have feedback relationship. Of course, there may have no relationship between the indexes [5].

2) To improve forecasting accuracy. The prediction may be improved if the sequence can be used to find the pattern together when the information of one sequence are contained in the historical data of anther [6].

\subsection{Structural Analysis}

Managers may have some expectation for the relationship between indexes in company's operation. But in empirical analysis, analysts hope to be able to verify the existence of these relationships through data. The Granger causality determination is a common approach to do such analysis. Structural causality test of multiple indexes has always been a highly controversial topic in the statistical analysis field. Many experts in natural science emphasized that the causal relationship can be clearly distinguished only in the experimental environment. While it is impossible to prove the existence of causal relationship only with observation data, what we can only do is to test the existence of dependence relationship. The fact is most of the data in social science are observing record. We can't control the environment where data generate, we can only observe it. But many experts in the social sciences still want to distinguish the different characteristics of indexes' correlation. Professor Granger (1969) put forward the Granger Causality concept. Consider two indexes $\mathrm{x}$ and $\mathrm{y}$, the sufficient condition that $\mathrm{y}$ has a one-way causal relationship of $\mathrm{x}$ is that the average forecast error will decrease if the information of index $y$ is introduced when do the prediction of index $x$ but the average forecast error won't change if the information of index $\mathrm{x}$ is used when we predict the value of index $\mathrm{y}$. Use the following symbols to represent the indexes: $\left\{x_{t}, y_{t}\right\}, t=1,2, \ldots, T$, the conditional variances are:

$$
\begin{aligned}
& \sigma_{x \mid-}^{2}=\operatorname{Var}\left(x_{t} \mid x_{t-1}, x_{t-2}, \cdots\right) \\
& \sigma_{x \mid y-}^{2}=\operatorname{Var}\left(x_{t} \mid x_{t-1}, x_{t-2}, \ldots, y_{t-1}, y_{t-2}, \cdots\right) \\
& \sigma_{x \mid y+}^{2}=\operatorname{Var}\left(x_{t} \mid x_{t-1}, x_{t-2}, \ldots, y_{t}, y_{t-1}, y_{t-2}, \cdots\right)
\end{aligned}
$$

$\sigma_{x \mid-}^{2}$ is the error variance when the past information of index $\mathrm{x}$ is used to predict index x.

$\sigma_{x \mid y-}^{2}$ is the error variance when the past information of index $\mathrm{x}$ and $\mathrm{y}$ are both used to predict index $\mathrm{x}$.

$\sigma_{x \mid y+}^{2}$ is the error variance when the past information of index $x, y$ and the simultaneous information of index $\mathrm{y}$ are used to predict index $\mathrm{x}$.

The Granger causality that index y has a one-way effect of index x can be expressed as

$$
\sigma_{x \mid y-}^{2}<\sigma_{x \mid-}^{2}, \quad \sigma_{y \mid x-}^{2}=\sigma_{y \mid-}^{2}
$$


As shown in Table 1, Piece (1979) and Geweke (1987) divided the Granger causality into the following eight dynamic relationships more specifically after the concept of causality is proposed by Granger.

Suppose the following VARMA time series model are applicable for indexes:

$$
\begin{gathered}
\left(\begin{array}{ll}
\Phi_{11}(B) & \Phi_{12}(B) \\
\Phi_{21}(B) & \Phi_{22}(B)
\end{array}\right)\left(\begin{array}{l}
x_{t} \\
y_{t}
\end{array}\right)=\left(\begin{array}{l}
c_{1} \\
c_{2}
\end{array}\right)+\left(\begin{array}{ll}
\Theta_{11}(B) & \Theta_{12}(B) \\
\Theta_{21}(B) & \Theta_{22}(B)
\end{array}\right)\left(\begin{array}{l}
a_{1 t} \\
a_{2 t}
\end{array}\right) \\
\left(\begin{array}{l}
a_{1 t} \\
a_{2 t}
\end{array}\right) \sim N\left(\left(\begin{array}{l}
0 \\
0
\end{array}\right)\left(\begin{array}{ll}
\sigma_{11} & \sigma_{12} \\
\sigma_{21} & \sigma_{22}
\end{array}\right)\right)
\end{gathered}
$$

Error vectors obey multivariate normal distribution. The average vector is zero vector and variance matrix is $\left(\begin{array}{ll}\sigma_{11} & \sigma_{12} \\ \sigma_{21} & \sigma_{22}\end{array}\right)$ 2).

Eight dynamic relationships between the two indexes can be tested by the following eight hypothesis (Table

\subsection{Trend Analysis and Prediction}

There are many methods in prediction technology, such as continuous method, artificial neural network, fuzzy logic method and support vector machine. According to the characteristics of State Grid, the basic idea of the prediction in this paper is: regard the object's data sequence formed over time as a random sequence and use a mathematical model to approximately describe it. The model can predict the future value from the past and present value of the time series once it is recognized. Modern statistical methods and econometric models have been able to help companies predict the future to some extent.

\begin{tabular}{|c|c|}
\hline Symbols & Dynamic relationships \\
\hline$x \wedge y$ & $x$ and $y$ are independent \\
\hline$x \leftrightarrow y$ & $x$ and $y$ are contemporaneous correlative \\
\hline$y \Rightarrow x$ & Use the past and simultaneous information of $y$ to predict $x$ \\
\hline$y \Rightarrow>x$ & Use the past information of $y$ to predict $x$ \\
\hline$x \Rightarrow y$ & Use the past and simultaneous information of $x$ to predict $y$ \\
\hline$x \Rightarrow>y$ & Use the past information of $x$ to predict $y$ \\
\hline$x \Leftrightarrow y$ & The past and simultaneous of $x$ and $y$ are interactive \\
\hline$x<\Leftrightarrow>y$ & The past of $x$ and $y$ are interactive \\
\hline
\end{tabular}

Table 1. Eight dynamic relationships.

Table 2. Eight hypothesis testing.

\begin{tabular}{cc}
\hline hypothesis & parameters \\
\hline$H_{1}$ & $\Phi_{12}=\Phi_{21}=\Theta_{12}=\Theta_{21}=\sigma_{12}=\sigma_{21}=0$ \\
$H_{2}$ & $\Phi_{12}=\Phi_{21}=\Theta_{12}=\Theta_{21}=0, \sigma_{12} \neq 0$ \\
$H_{3}$ & $\Phi_{21}=\Theta_{21}=0, \sigma_{12} \neq 0, \Phi_{12} \neq 0$ \\
$H_{3}^{*}$ & $\Phi_{21}=\Theta_{21}=\sigma_{12}=0, \Phi_{12} \neq 0$ \\
$H_{4}$ & $\Phi_{12}=\Theta_{12}=0, \sigma_{12} \neq 0, \Phi_{21} \neq 0$ \\
$H_{4}^{*}$ & $\Phi_{12}=\Theta_{12}=\sigma_{21}=\sigma_{12}=0, \Phi_{21} \neq 0$ \\
$H_{5}$ & $\Phi_{12} \Phi_{21} \sigma_{12} \neq 0$, or $\sigma_{12} \Theta_{21} \Theta_{12} \neq 0$ \\
$H_{5}^{*}$ & $\sigma_{21}=\sigma_{12}=0, \Phi_{12} \Phi_{21} \neq 0, \Theta_{21} \Theta_{12} \neq 0$ \\
\hline
\end{tabular}


The basic process of predict model:

(1) Identify the stability of the sequence according to the scatter plot, the autocorrelation function diagram and partial autocorrelation function diagram, unit root rest, trend and seasonal variation. Generally, the time series of economic operation is not a smooth sequence.

(2) Stationary processing for the non-stationary series. We need to do difference disposal if the series is nonstationary and there is a certain growth or decline in the sequence. If heteroscedasticity exits in the data, we need to process the data until the values of the autocorrelation function and partial correlation function were not significantly different from zero [7].

(3) Establish the appropriate model according to the recognition rules based on time series model. The sequence is suitable for AR model if the partial correlation function is truncated and the autocorrelation function is trailing. The sequence is suitable for MA model if the partial correlation function is trailing and the autocorrelation function is truncated. If both the partial correlation function and the autocorrelation function are trailing, then ARMA model is the suitable model for the sequence.

(4) Do the parameter estimation and test if it is statistical significant.

(5) Do the hypothesis testing to diagnose whether the residuals are white noise.

(6) Use the verified model to do predictive analysis.

Forecasting model mainly includes single index time series model, transformation function model and multi index vector time series model (VARMA).

\subsection{Early Warning Analysis}

The key in early warning analysis lies in the setting of threshold. The goal of setting threshold is to set boundary between the normal and abnormal values. So the distribution of the control value and the actual value is the core issue. Generally speaking, the normal value is more common and appears more frequently while abnormal values often deviate from the conventional value. Therefore by analyzing the change of its values and determining its distribution we can set the corresponding threshold according to the characteristics of the distribution [8].

However, most indexes in business operations will not repeat. In this paper, we analyze the historical value of the index and determine the distribution it obeys. For the values at each point of time, we use other data in the sample to predict it and calculate the prediction error. If the model is suitable for the data, the prediction error should obey a normal distribution. We can calculate the difference (the prediction error) between the actual observation value and the expected value to judge whether the index is normal. And then we can draw the conclusion from the comparison of the normal rage of prediction error and the normal distribution.

The normal range of a random variable which obeys the normal distribution depends on the identification of abnormality and whether the normal range is symmetrical (the expected value is not too large nor too small). If the normal range is a left-skewed distribution the expected value will be small. If the normal is a right-skewed distribution the expected value will large. In accordance with the distribution of standard deviation and prediction error, the threshold value can be obtained [9].

\section{An Empirical Analysis of the State Grid}

In this section, taking the total net revenues, total electricity sales and the total purchase of electricity as an example, we conduct an empirical analysis of the State Grid based on the data of one province from January 2010 to June 2015.

The time sequence diagram of total net revenues, total electricity sales and the total purchase of electricity is shown in Figure 2.

The purchase of electricity in a period should match the electricity sales in the next period under normal and reasonable mode of operation. Socio-economic needs for electricity usually have a certain degree of inertia. The sales of electricity in the past months can be used to predict the sales in next months. According to this logic, the purchase of electricity in the future will be affected by the sales in the past. From financial perspective total net revenues is affected by the total electricity sales, total purchase and other operation costs. The most effective factor in deciding the total net revenues is also useful information for the management. Causality analysis of every two indexes can be used in practical application. Firstly, the vector model of purchase and sales is built as follow: 


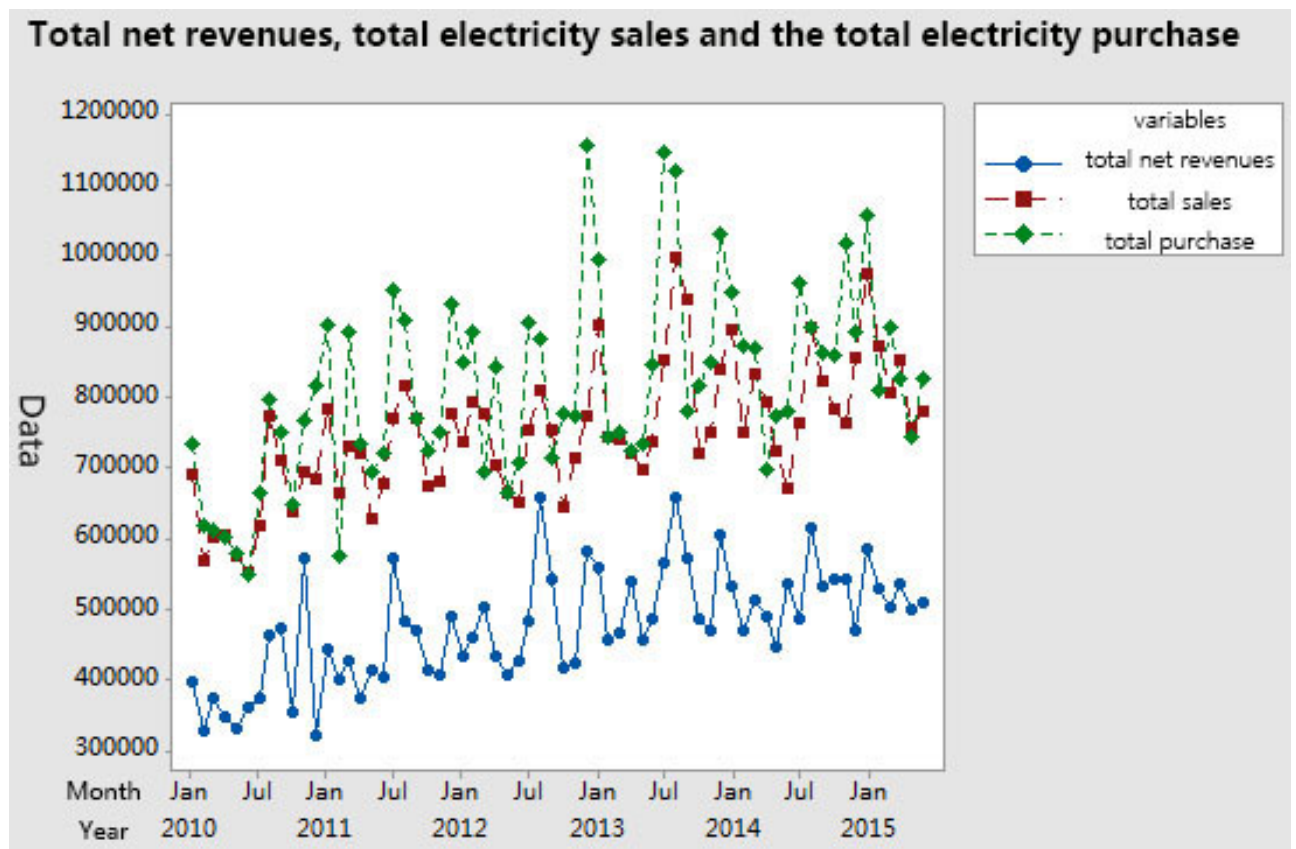

Figure 2. Time sequence diagram of total net revenues, total sales and total purchase.

$$
\begin{aligned}
& \left(I-\left(\begin{array}{ll}
0.07 & -0.31 \\
0.35 & -0.03
\end{array}\right) B-\left(\begin{array}{cc}
0.28 & 0.36 \\
-0.01 & 0.40
\end{array}\right) B^{12}\right)\left(\begin{array}{l}
\log \left(\text { buy }_{t}\right) \\
\log \left(\text { sell }_{t}\right)
\end{array}\right)=\left(\begin{array}{l}
8.28 \\
3.99
\end{array}\right)+\left(\begin{array}{c}
a_{1 t} \\
a_{2 t}
\end{array}\right) \\
& \Sigma=\left(\begin{array}{ll}
0.013 & 0.005 \\
0.005 & 0.004
\end{array}\right)
\end{aligned}
$$

The variation matrix of the error vector is $\Sigma=\left(\begin{array}{ll}0.013 & 0.005 \\ 0.005 & 0.004\end{array}\right)$. The same results are obtained by using forward and backward test methods:

Purchase $=>$ Sales (the total electricity sales are affected by the purchase)

Result shows that the purchase in the past and in the same period affects the sales of electricity, which is not consistent with the previous discussion. In other words, the sales in the past wasn't taken into consideration when purchase under the current mode of operation. The diagnosis results indicate the possible direction of future operation. By using the same method we can get:

Net revenues <-> Total purchase of electricity (contemporaneous correlative)

Net revenues $\wedge$ Total electricity sales (independent)

As shown in Figure 3, the total net revenue is contemporaneous correlative with total electricity purchase but it has nothing to do with the total electricity sales. The result is consistent with the monopoly operation of State Grid. The analysis above pointed the purchase is not affected by the sales but on the contrary the sale is subject to purchase. If the strategic objective is to improve the service quality or operational efficiency the purchase department should adjust the purchase process to let the sales guide the purchase.

If the business strategy has expected target for these three indexes, diagnostic system can forecast each individual, as shown in Figure 4.

These results can be compared with the strategic objectives and external economic indicators like regional economic output, regional consumption and sales and so on. If the department leaders are concerned about the early warning analysis of total net revenues, total electricity purchase and total electricity sales, the diagnostic system can do the following analysis.

Light blue means moderately lower than expectation $(-1)$. Dark blue is significantly below expectation $(-2)$. Pink means moderately higher than expectation (1). Red is for a large range of overheating (2) (Table 3). 


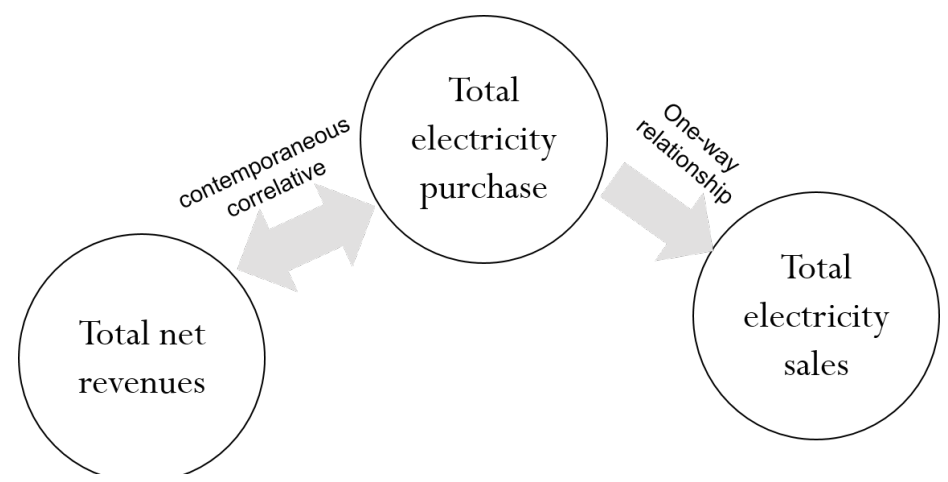

Figure 3. Relationships among total net revenues, total electricity sales and total electricity purchase.

Table 3. Early warning analysis.

\begin{tabular}{|c|c|c|c|}
\hline \multicolumn{4}{|c|}{ Early warning analysis } \\
\hline Month & Total net revenues & Total sales & Total purchase \\
\hline Jan.2014 & 0 & 0 & 0 \\
\hline Feb.2014 & 0 & -1 & 0 \\
\hline Mar.2014 & 0 & 0 & 0 \\
\hline Apr.2014 & 0 & 0 & -1 \\
\hline May.2014 & 0 & 0 & 0 \\
\hline Jun.2014 & 0 & -1 & 0 \\
\hline Jul.2014 & -1 & -1 & 0 \\
\hline Aug.2014 & -1 & 0 & -1 \\
\hline Sept.2014 & -1 & 0 & 0 \\
\hline Oct.2014 & 0 & 1 & 0 \\
\hline Nov.2014 & 0 & -1 & 0 \\
\hline Dec.2014 & -2 & 0 & -1 \\
\hline Jan.2015 & 0 & 0 & 0 \\
\hline Feb.2015 & 0 & 0 & 0 \\
\hline Mar.2015 & 0 & -1 & 0 \\
\hline Apr.2015 & 0 & 1 & 0 \\
\hline May.2015 & 0 & 0 & 0 \\
\hline Jun.2015 & 0 & 0 & 0 \\
\hline
\end{tabular}

\section{Discussion}

Operation diagnosis system is a main tool to help improve the management efficiency of enterprises. It is necessary for enterprise shareholders to periodically check whether the operation is in conformity with the established strategic objectives. If the strategy is not fulfilled, the operation diagnosis system must explicitly point out the imperfections of business processes and instruct the relevant units to make improvement immediately. The key technologies in the company's operations and diagnostic analysis methods were introduced in this paper. Then, empirical models was built based on the operational data of State Grid, the performance of the company was assessed to help find the problems in operations. This study provided the basis for the enterprises to monitor 

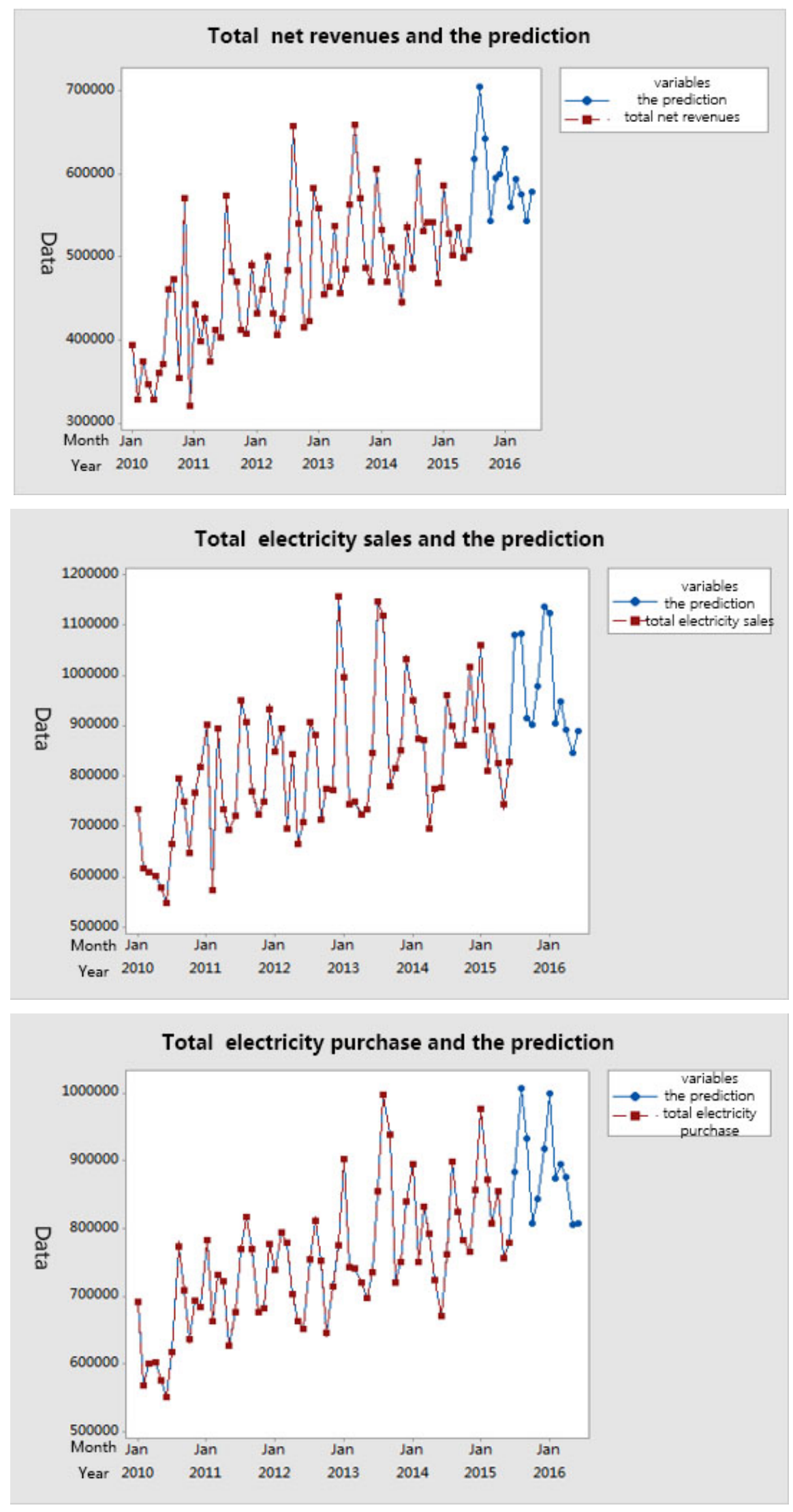


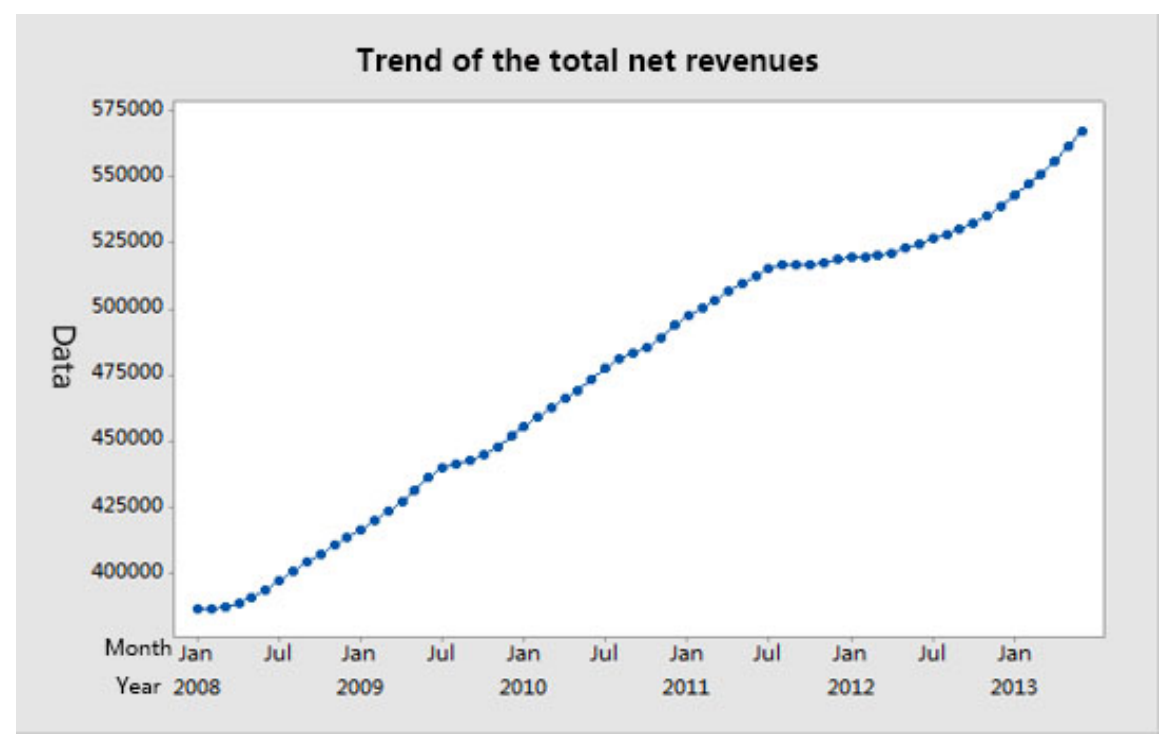

Figure 4. Trends and forecasts of the indexes.

and understand the influence of the market or other external factors on the implementation of the enterprise strategic objectives.

\section{References}

[1] Li, Q., Chen, L.-L. and Ma, K. (2014) Analysis on Construction of Energy Enterprise Project Management System. The Journal of New Industry, 4, 96-101.

[2] Yin, C., Gan, D.-W., Liang, Z.-Q. and Fei, Y.-C. (2013) Evaluation and Early Warning Method of Key Assembly Process Materials Quality Loss for Complex Electromechanical Products. Computer Integrated Manufacturing Systems, 3, 31-43.

[3] Wang, X., Li, S.G., Qin, B. and Liu, J.J. (2014) Wind Power Prediction Based on Fuzzy Support Vector Machine. The Journal of New Industry, 4, 50-55.

[4] Wang, X. and Liu, J.J. (2014) Short-Term Load Forecasting Based on Bayes’ Theorem Support Vector Machine. The Journal of New Industry, 4, 20-24.

[5] Lin, L.-Q., Chen, S.-J. and Tan, Z.-F. (2014) Fuzzy Fault Tree Analysis Model for Grid Operation Risk Warning Evaluation. East China Electric Power, 42, 229-233.

[6] Dong, Y.G., Zhu, W.Y. and Chen, X.C. (1996) Fuzzy Fault Tree Analysis and Its Application. Journal of Hefei University of Technology, 19, 36-40.

[7] Li, C.-J., Leng, Y. and Sun, J.-Q. (2011) Synergistic Evolutionary Model Dynamic Evaluation of Electricity Marker Efficiency. East China Electric Power, 39, 1563-1567.

[8] Zhou, J.-G. and Wang, X.-W. (2007) Game Theory and Gray Incidence Degree Based Appraisement Index System for Operation Effect of Regional Electricity Market. Power System Technology, 31, 69-73.

[9] Chen, S.-J., Yang, G.-Z., Huang, D.-S. and Wu, D.-Y. (2012) AHP Application to Power Grid Operation Efficiency Evalution. East China Electric Power, 40, 1891-1894. 


\section{Submit or recommend next manuscript to SCIRP and we will provide best service for you:}

Accepting pre-submission inquiries through Email, Facebook, LinkedIn, Twitter, etc.

A wide selection of journals (inclusive of 9 subjects, more than 200 journals)

Providing 24-hour high-quality service

User-friendly online submission system

Fair and swift peer-review system

Efficient typesetting and proofreading procedure

Display of the result of downloads and visits, as well as the number of cited articles

Maximum dissemination of your research work

Submit your manuscript at: http://papersubmission.scirp.org/ 